\title{
Efektivitas Pemberian Cairan Praoperatif Ringer Laktat 2 mL/kgBB/jam Puasa untuk Mencegah Mual Muntah Pascaoperasi
}

\author{
Andi Ade Wijaya, Bona A. Fithrah, Arif H. M. Marsaban, Jefferson Hidayat \\ Departemen Anestesiologi dan Intensive Care \\ Fakultas Kedokteran Universitas Indonesia/RSUPN Cipto Mangunkusumo
}

\begin{abstract}
Abstrak
Teknik nonfarmakologi yang dapat dilakukan untuk menurunkan angka kejadian mual muntah pascaoperasi adalah pemberian cairan praoperatif. Tujuan penelitian ini untuk mengetahui efektivitas pemberian cairan praoperatif Ringer laktat $2 \mathrm{~mL} / \mathrm{kgBB} / \mathrm{jam}$ puasa untuk menurunkan angka kejadian mual muntah pascamastektomi. Penelitian ini merupakan uji klinis acak yang dilakukan pada bulan Maret-April 2013 di Rumah Sakit Kanker Dharmais, Rumah Sakit Persahabatan, Rumah Sakit Fatmawati, dan Rumah Sakit Cipto Mangunkusumo Jakarta, pada pasien status fisik American Society of Anesthesiologist (ASA) 1-2. Sebanyak 102 pasien diacak ke dalam kelompok hidrasi dan kelompok kontrol. Analisis data dilakukan menggunakan uji chi-kuadrat. Terdapat perbedaan yang signifikan dalam kejadian mual pada 0-1 jam pascaoperasi (kelompok hidrasi 20\% vs kelompok kontrol 39\%) dan pada 0-24 jam pascaoperasi (kelompok hidrasi $22 \%$ vs kelompok kontrol $41 \%$ ). Walaupun tidak berbeda secara statistik, angka kekerapan mual pada 1-24 jam pascaoperasi lebih rendah pada kelompok hidrasi 12\% (6) dibandingkan dengan kelompok kontrol 23\% (12). Tidak ada perbedaan secara statistik pada angka kekerapan muntah di kedua kelompok penelitian. Pemberian cairan praoperatif Ringer laktat $2 \mathrm{~mL} / \mathrm{kgBB} / \mathrm{jam}$ puasa efektif untuk menurunkan angka kejadian mual pascaoperasi mastektomi pada 1 jam pertama pascaoperasi.
\end{abstract}

Kata kunci: Cairan praoperatif, mastektomi, mual muntah pascaoperasi

\section{Effectiveness of Pre-operative Lactated Ringer's Solution $2 \mathrm{~mL} / \mathrm{kgBW} / \mathrm{h}$ in Fasting Patients to Prevent Post-operative Nausea and Vomiting}

\begin{abstract}
Non pharmacologic approaches to overcome post operative nausea and vomiting include giving preoperative hydration. The objective of this study was to learn the efficacy of pre-operative lactated Ringer's solution ( $2 \mathrm{~mL} / \mathrm{kgBW} /$ hour $)$ in fasting patients to overcome the post-operative nausea and vomiting in mastectomy surgery. This study was a randomized clinical trial that conducted in March to April 2013 in Dharmais Hospital-National Cancer Center, Persahabatan Hospital, Fatmawati Hospital, and Rumah Sakit Cipto Mangunkusumo Jakarta to patients with American Society of Anesthesiologist (ASA) physical status 1-2. A total of 102 patients were randomized into the hydration group and control group. Data analysis was performed using chi-square test or appropriate test using SPSS ver. 15. There were statistically significant differences in the incidence of nausea at $0-1$ hour post-operative $(19.6 \%$ in hydration group vs. $39.2 \%$ in control group) and at $0-24$ hours post-operative ( $21.6 \%$ in hydration group vs. $41.2 \%$ control group). The incidence of 1-24 hours PONV, although not statistically significant, was higher in the control group $111.8 \%$ in hydration group vs. $23.5 \%$ in control group). There was no difference in vomiting incidence between the two groups. Pre-operative lactated Ringer's solution $2 \mathrm{~mL} / \mathrm{kgBW} /$ hour in fasting patients effectively reduces the incidence of post-operative nausea one hour after operation.
\end{abstract}

Key words: Mastectomy, post-operative nausea and vomiting pre-operative hydration

Korespondensi: Andi Ade Wijaya, dr., Sp.An(K), Departemen Anestesiologi dan Terapi Intensif/RSUPN Cipto Mangunkusumo, Jl. P. Diponegoro No. 71 Jakarta, Telp. 021-3143736, Mobile 08121038091, Email adwrfauzi@gmail.com 


\section{Pendahuluan}

Mual muntah pascaoperasi masih merupakan masalah yang sering kali terjadi pada pasien yang menjalani pembedahan dalam anestesia umum. Sekitar 71 juta orang pasien per tahun menjalani pembedahan di Amerika Serikat, dengan insidens kejadian mual dan muntah pascaoperasi berkisar $20-30 \%$ dari seluruh pembedahan umum dan lebih kurang $70-80 \%$ pada kelompok risiko tinggi. ${ }^{1}$

Habib dan Gan $^{2}$ menyatakan bahwa insidens mual muntah pascaoperasi payudara berkisar 50-65\%,sedangkan pada kepustakaan lain adalah $80 \%{ }^{3}$ Angka kejadian ini sangat tinggi, di tengah penggunaan obat antimual muntah baru serta penggunaan teknik anestesia yang kurang emetogenik. ${ }^{4}$ Sebagian besar penelitian mual muntah pascaoperasi tersebut dilakukan pada operasi per laparoskopi, sedangkan pada mastektomi masih jarang.

Berbagai pendekatan dan juga investigasi klinis dilakukan untuk menurunkan insidens kejadian mual muntah pascaoperasi. Uji klinis yang terbaru menunjukkan bahwa pendekatan multimodal dalam pemberian obat antiemetik mampu menurunkan kejadian mual muntah, meningkatkan kepuasan, serta mempercepat masa pemulihan pasien. ${ }^{5}$ Metode pendekatan multimodal ini menggunakan cara farmakologi dan nonfarmakologi. ${ }^{6}$

Salah satu pendekatan nonfarmakologi yang murah, mudah, serta aman adalah mencukupi status hidrasi. ${ }^{6,7}$ Beberapa penelitian dilakukan untuk mengetahui pengaruh pemberian cairan praoperatif terhadap kejadian mual muntah pascaoperasi. ${ }^{4,6,8}$ Penelitian tersebut dilakukan melalui berbagai cara serta intervensi, seperti jumlah, tipe, dan waktu pemberian cairan.

Mencegah mual muntah dengan pemberian cairan praoperatif ini efektif diterapkan pada pembedahan one day care (ODC) dengan lama operasi 20-30 menit, tetapi belum dilakukan penelitian pada operasi elektif dengan durasi operasi 150 menit. Mastektomi adalah salah satu jenis pembedahan yang memiliki angka kejadian mual muntah yang tinggi dan durasi operasi berkisar 150 menit.

Berdasarkan masalah dan juga kontroversi yang terjadi, penelitian ini bertujuan untuk mengetahui bagaimana efektivitas pemberian Ringer laktat sebanyak $2 \mathrm{~mL} / \mathrm{kgBB} / \mathrm{jam}$ puasa yang diberikan praoperatif dalam mengurangi kejadian mual mutah pascabedah mastektomi.

\section{Subjek dan Metode}

Penelitian ini merupakan uji klinis acak untuk mengetahui efek pemberian cairan praoperatif Ringer laktat $2 \mathrm{~mL} / \mathrm{kgBB} / \mathrm{jam}$ puasa dan dibagi dalam dua kelompok, yaitu kelompok hidrasi, kelompok kontrol dan juga tanpa pemberian cairan praoperatif. Penelitian ini dilakukan di Rumah Sakit Kanker Dharmais, Persahabatan, Fatmawati, dan Cipto Mangunkusumo Jakarta periode Maret-April 2013. Populasi penelitian ini ialah pasien yang menjalani operasi bedah mastektomi.

Kriteria inklusi, yaitu wanita yang menjalani pembedahan mastektomi, berusia 18 hingga 62 tahun, dengan status fisik American Society of Anesthesiologist (ASA) 1-2, bersedia menjadi peserta penelitian dan juga menandatangani formulir persetujuan, tidak ada riwayat mual muntah atau motion sickness, tidak menderita kelainan/gangguan jantung.

Kriteria eksklusi,yaitusedangmengonsumsi antiemetik secara rutin atau mempergunakan antiemetik sesaat sebelum dilakukan operasi, perokok, serta pasien yang pernah menjalani operasi telinga bagian dalam.

Kriteria pengeluaran, yaitu terjadi hipotensi intraoperatif, perdarahan masif intraoperatif, tindakan operasi bertambah atau dilanjutkan dengan tindakan lain, operasi lebih dari 2,5 jam, dan perawatan pascaoperasi dilakukan di Unit Perawatan Intensif. Data disajikan dalam bentuk tekstular dan juga tubular. Untuk data nonparametrik dilakukan analisis statistika mempergunakan uji chi-kuadrat atau uji yang sesuai dengan mengunakan statistical product and servise solution (SPSS) ver. 15. Perbedaan bermakna jika $\mathrm{p}<0,05$.

\section{Hasil}

Pasien yang diambil sebagai subjek penelitian sebanyak 109 pasien. Penelitian ini dilakukan 


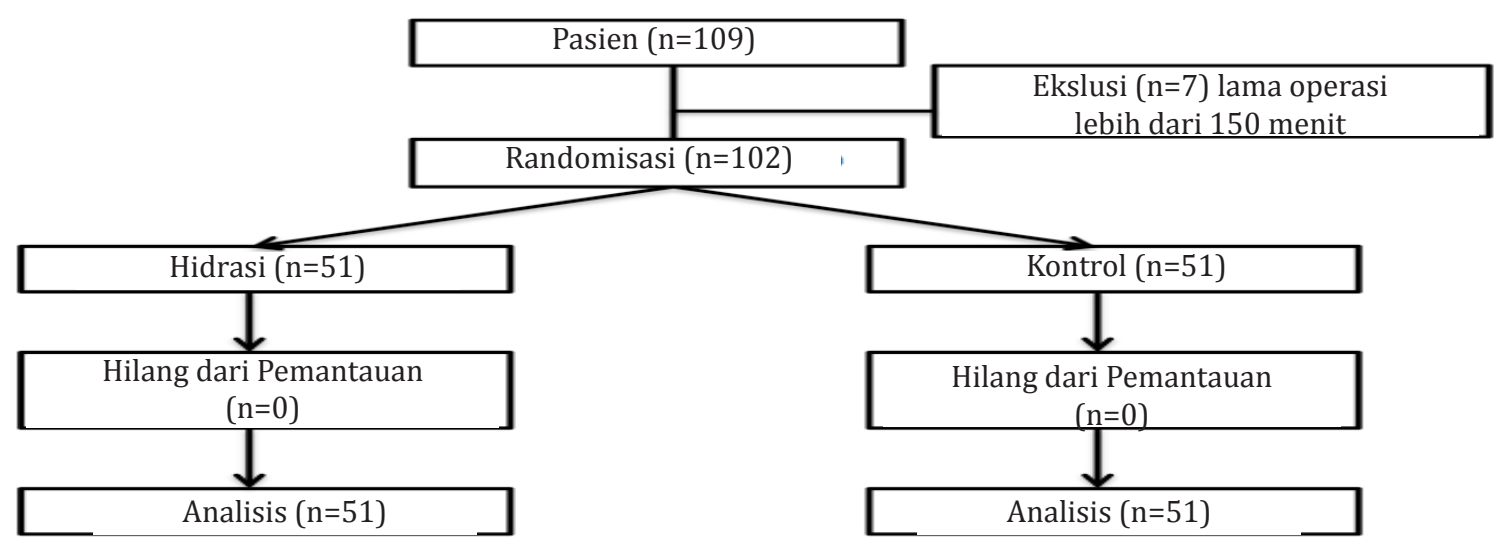

Gambar 1 Diagram Alur Proses Pengambilan Sampel

pada periode Maret-April 2013. Pengambilan sampel dilakukan di Rumah Sakit (RS) Kanker Dharmais, RS Persahabatan, RS Fatmawati, serta RS Cipto Mangunkusumo. Subjek diambil dari RS Persahabatan sebanyak 6 pasien, RS Fatmawati 10 pasien, RS Cipto Mangunkusumo 2 pasien, sedangkan RS Kanker Dharmais 91 pasien. Tujuh orang pasien dikeluarkan dari penelitian karena dilanjutkan dengan tindakan rekonstruksi hingga lama operasi $>150$ menit. Pemantauan dilakukan selama di ruang pulih dan di ruang perawatan selama 24 jam.

Dari Tabel 1 demografik serta karakteristik sampel dapat ditarik kesan bahwa pasien yang menjalani penelitian, yaitu kelompok kontrol dan hidrasi tidak berbeda (setara).

Angka kejadian mual 0-1 jam pascaoperasi pada kelompok hidrasi ialah 10 orang (20\%), sedangkan kelompok kontrol 20 orang (39\%). Berdasarkan analisis statistika menggunakan uji chi-kuadrat didapatkan perbedaan yang bermakna $(p<0,05)$. Angka kejadian muntah 0-1 jam pascaoperasi pada kelompok hidrasi sebanyak 7 orang (14\%), sedangkan kelompok kontrol yaitu 6 orang (12\%) dengan perbedaan yang bermakna berdasarkan pada hasil uji chi kuadrat ( $p>0,05$; Tabel 2).

Angka kejadian mual 1-24 jam pascaoperasi

Tabel 1 Demografik dan Karakteristik Sampel yang Menjalani Penelitian

\begin{tabular}{lcc}
\hline \multicolumn{1}{c}{ Variabel } & Hidrasi (n=51) & Kontrol (n=51) \\
\hline Usia (tahun) & $48,73 \pm 8,01$ & $44,75 \pm 9,89$ \\
IMT $\left(\mathrm{kg} / \mathrm{m}^{2}\right)$ & $23,44(18,37-35,16)$ & $23,75 \pm$ \\
Skor Apfel & $3(3-3)$ & $3(3-3)$ \\
Lama puasa (jam) & $8,0(6,0-12,0)$ & $8,0(8,0-13,0)$ \\
ASA 1 & $23(45 \%)$ & $36(71 \%)$ \\
ASA 2 & $28(55 \%)$ & $15(29 \%)$ \\
Lama operasi (menit) & $130,0(75,0-150,0)$ & $130,0(60,0-145,0)$ \\
Lama pembiusan & $140,0(90,0-150,0)$ & $145,0(75,0-150,0)$ \\
Cairan praoperatif & $1.200,0(800-1.500)$ & 0 \\
Cairan intraoperatif & $1.000,0(100,0-2.500,0)$ & $1.000,0(500,0-1.500,0)$ \\
Total pendarahan $(\mathrm{mL})$ & $200,0(100,0-600,0)$ & $200,0(50,0-500,0)$ \\
Jumlah neostigmin & $1,0(0,5-2,0)$ & \\
\hline
\end{tabular}

Keterangan: data numerik distribusi normal rata-rata \pm SB; distribusi tidak normal median (minimum-maksimum) 
Tabel 2 Kekerapan Mual Muntah

\begin{tabular}{|c|c|c|c|c|}
\hline Variabel & Hidrasi $(n=51)$ & Kontrol $(n=51)$ & Nilai p & RR (95\% IK) \\
\hline \multicolumn{5}{|l|}{ 0-1 Jam } \\
\hline \multicolumn{5}{|l|}{ Mual } \\
\hline Ya & $10(20 \%)$ & $20(39 \%)$ & $0,030^{*}$ & $0,50(0,26-0,96)$ \\
\hline Tidak & $41(80 \%)$ & $31(61 \%)$ & & \\
\hline \multicolumn{5}{|l|}{ Muntah } \\
\hline Ya & $7(14 \%)$ & $6(12 \%)$ & $0,767^{*}$ & $1,17(0,42-3,23)$ \\
\hline Tidak & $44(86 \%)$ & $45(88 \%)$ & & \\
\hline \multicolumn{5}{|l|}{ 1-24 Jam } \\
\hline \multicolumn{5}{|l|}{ Mual } \\
\hline Ya & $6(12 \%)$ & 12 (23\%) & $0,119 *$ & $0,50(020-1,23)$ \\
\hline Tidak & $45(88 \%)$ & $39(77 \%)$ & & \\
\hline \multicolumn{5}{|l|}{ Muntah } \\
\hline Ya & $3(6 \%)$ & $3(6 \%)$ & $1,000^{*}$ & $1,00(0,21-4,72)$ \\
\hline Tidak & $48(94 \%)$ & 48 (94\%) & & \\
\hline \multicolumn{5}{|l|}{ 0-24 Jam } \\
\hline \multicolumn{5}{|l|}{ Mual } \\
\hline Ya & $11(22 \%)$ & $21(41 \%)$ & $0,033^{*}$ & $0,52(0,28-0,97)$ \\
\hline Tidak & $40(78 \%)$ & $30(59 \%)$ & & \\
\hline \multicolumn{5}{|l|}{ Muntah } \\
\hline Ya & $7(14 \%)$ & $7(14 \%)$ & $1,000^{*}$ & $1,00(0,38-2,65)$ \\
\hline Tidak & $44(86 \%)$ & $44(86 \%)$ & & \\
\hline
\end{tabular}

Keterangan: * uji chi-kuadrat, * Uji Fisher

pada kelompok hidrasi adalah 6 orang (12\%), sedangkan pada kelompok kontrol 12 orang (23\%), dengan menggunakan uji chi-kuadrat didapatkan nilai $\mathrm{p}=0,119$ (nilai $\mathrm{p}>0,05)$. Angka kejadian muntah 1-24 jam pascaoperasi pada kelompok hidrasi sebanyak tiga orang (6\%), sedangkan kelompok kontrol juga tiga orang (6\%). Dengan menggunakan Uji Eksak Fisher didapatkan $\mathrm{p}=1(\mathrm{p}>0,05)$.

Kejadian mual saat 0-24 jam pascaoperasi pada kelompok hidrasi adalah 11 orang (22\%), sedangkan kelompok kontrol adalah 21 orang (41\%), berdasarkan hasil analisis memakai uji chi-kuadrat didapatkan perbedaan bermakna $(\mathrm{p}<0,05)$. Angka kejadian muntah 0-24 jam pascaoperasi pada kelompok hidrasi dan juga kontrol masing-masing adalah 7 (tujuh) orang (14\%). Berdasarkan analisis mempergunakan uji chi-kuadrat didapatkan perbedaan yang tidak bermakna berdasarkan statistik $(p>0,05)$. Risiko relatif terjadi mual muntah pascaoperasi adalah $0,52(0,28-0,97)$ kali pada pasien yang mendapat cairan praoperatif Ringer laktat 2 $\mathrm{mL} / \mathrm{kgBB} / \mathrm{jam}$ puasa, dibandingkan dengan yang tidak diberikan cairan (Tabel 2).

\section{Pembahasan}

Mual dan muntah pascaoperasi masih menjadi masalah besar di dalam praktik anestesia. Saat penggunaan antiemetik telah rutin dilakukan, perkembangan obat-obatan antiemetik baru, metode/pendekatan baru dan juga panduan baru, ternyata risiko terjadi mual dan muntah pascaoperasi masih tinggi. Pada pasien elektif angka kejadian mual dan muntah pascaoperasi 


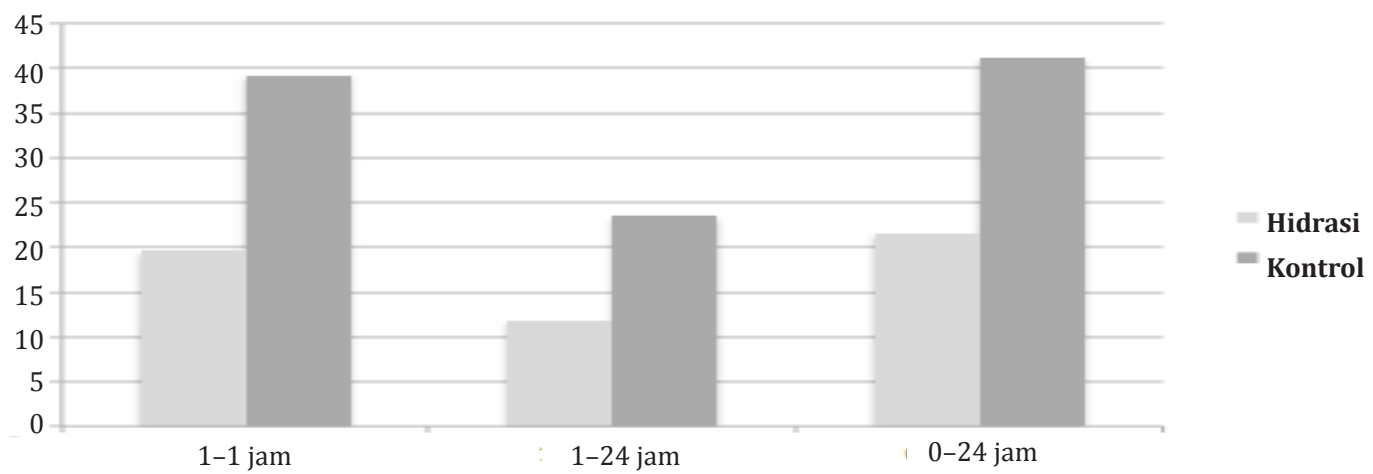

Gambar 2 Diagram Batang Angka Kejadian Mual Muntah Pascaoperasi Mastektomi

adalah 30\%, sedangkan pada kelompok risiko tinggi adalah $70-80 \%$ bila tanpa penggunaan antiemetik. $^{5}$

Pasien yang menjalani operasi mastektomi mempunyai risiko yang tinggi. Angka kejadian mual muntah pascaoperasi pasien mastektomi sekitar 55-80\% ${ }^{2,3,9,10}$ Kejadian mual muntah pascaoperasi mastektomi di Indonesia belum diketahui pasti, namun bila melihat risiko yang dimiliki pasien yang menjalani mastektomi diduga memiliki angka kejadian mual muntah pascaoperasi tinggi.

Pada penelitian ini, insidens mual muntah dalam 24 jam pascaoperasi adalah 31\%. Angka kejadian ini tidak jauh berbeda dengan angka kejadian mual dan muntah pada pasien elektif tetapi berbeda jauh pada angka mual muntah pascaoperasi pada pasien risiko tinggi. ${ }^{5}$ Angka kejadian 31\% ini juga berbeda dengan angka kejadian mual dan muntah pascaoperasi pada pasien yang menjalani operasi mastektomi pada penelitian Sadharivan dkk. ${ }^{10}$

Risiko mual dan muntah pascaoperasi pada pasien yang menjalani prosedur mastektomi ditentukan menggunakan Apfel Scoring System, yaitu jenis kelamin perempuan, riwayat mual dan muntah pascaoperasi sebelumnya, riwayat motion sickness sebelumnya, bukan perokok, dan penggunaan opioid pascaoperasi. ${ }^{11}$ Setiap faktor akan meningkatkan risiko terjadi mual muntah pascaoperasi sebesar $18-22 \%{ }^{11}$

Pada penelitian Maharaj dkk. ${ }^{12}$ terhadap 80 pasien yang menjalani ginekologi laparoskopi diagnostik mempergunakan cairan praoperatif compound sodium laktat $2 \mathrm{~mL} / \mathrm{kgBB} / \mathrm{jam}$ puasa mendapat angka kejadian mual muntah 59\% (hidrasi) vs 87\% (kontrol). Maharaj dkk. ${ }^{12}$ menyimpulkan penggunaan cairan praoperatif $2 \mathrm{~mL} / \mathrm{kgBB} / \mathrm{jam}$ puasa pada prosedur operasi rawat jalan dapat menurunkan angka kejadian mual muntah pascaoperasi.

Subjek penelitian Maharaj dkk. ${ }^{12}$ tersebut memiliki skor Apfel 3 (tiga), yaitu jenis kelamin perempuan, bukan perokok, dan menggunakan opioid pascaoperasi, ini berarti sampel yang digunakan pada penelitian tersebut termasuk kelompok high risk untuk terjadi mual muntah pascaoperasi. Lama operasi penelitian Maharaj dkk. ${ }^{12}$ adalah $22,4 \pm 2,7$ menit pada kelompok hidrasi serta 21,5 $\pm 3,4$ menit kelompok kontrol. Lama operasi ini merupakan salah satu faktor penentu kejadian mual muntah pascaoperasi, karena semakin lama operasi, maka semakin lama kontak pasien dengan gas-gas anestesia yang juga merupakan faktor penyebab mual muntah pascaoperasi. ${ }^{13}$

Maharaj dkk. ${ }^{12}$ melakukan penilaian mual muntah pascaoperasi di ruang pulih, 1, 4, 24, serta 72 jam pascaoperasi. Secara keseluruhan angka kejadian mual muntah pada kelompok hidrasi ternyata lebih rendah, dengan angka kejadian mual muntah di ruang pulih adalah $40 \%$ vs $60 \%, 1$ jam pascaoperasi $44 \%$ vs $75 \%, 4$ jam pascaoperasi $30 \%$ vs $65 \%, 24$ jam pascaoperasi $18 \%$ vs $65 \%$, serta 72 jam pascaoperasi $10 \%$ vs $40 \%{ }^{12}$

Berdasarkan analisis data demografik serta karakteristik penelitian ini, didapatkan bahwa semua pasien mempunyai skor Apfel 3, yaitu jenis kelamin perempuan, tidak merokok, dan 
menggunakan opioid pascaoperasi (tramadol $2 \mathrm{mg} / \mathrm{kgBB}$ ). Subjek penelitian ini termasuk pada kelompok risiko tinggi untuk terjadi mual muntah pascaoperasi, sama seperti penelitian Maharaj dkk. ${ }^{12}$

Data demografi dan karakteristik penelitian ini, didapatkan bahwa lama pembiusan pada kelompok hidrasi adalah 140 (90,0-150,0) menit serta pada kelompok kontrol adalah 145 (75,0-150,0) menit. Ini berbeda sekali dengan penelitian yang dilakukan oleh Maharaj dkk. ${ }^{12}$

Pada penelitian ini penilaian mual muntah hanya dilakukan dua kali, yaitu satu jam serta 24 jam pascaoperasi. Jarak waktu yang jauh dalam melakukan penilaian mual dan muntah pascaoperasi tersebut membuat peneliti tidak dapat menilai sampai berapa lama pemberian cairan praoperatif ini dapat menurunkan mual muntah pascaoperasi. Bila dilakukan penilaian kembali setelah 4 jam atau 6 jam pascaoperasi maka peneliti dapat melihat perubahan pada angka kejadian mual dan muntah pascaoperasi setelah 1 jam pascaoperasi.

Pendekatan mual dan muntah pascaoperasi saat ini, yaitu dengan pendekatan multimodal, pencegahan mual muntah yang dilakukan tidak hanya di akhir pembedahan dengan memakai dua-tiga obat sebagai pencegahannya tetapi dengan mengurangi risiko mual muntah sejak pra hingga pascaoperasi. ${ }^{1,2,14}$ Untuk melakukan hal ini dilakukan pendekatan baik farmakologi maupun nonfarmakologi.

Pemberian cairan saat praoperatif memang belum mendapatkan rekomendasi dari SAMBA sebagai teknik dalam pencegahan mual muntah pascaoperasi, tetapi pendekatan ini bukan hal yang baru, sudah banyak dilakukan uji coba tentang pendekatan ini dengan berbagai sudut pendekatan seperti jumlah, jenis, serta waktu pemberian cairan. . $7,712,15,16$

Penelitian tersebut ingin menilai efektivitas penggunaan cairan praoperatif sebagai salah satu metode mencegah kejadian mual muntah pascaoperasi. Penggunaan cairan praoperatif yang efektif tentu ditunjukkan dengan angka kejadian mual muntah pascaoperasi yang lebih rendah bila dibandingkan dengan kelompok kontrol.

Apfell dan Meyer ${ }^{17}$ menyatakan pemberian kristaloid pada saat praoperatif pada beberapa penelitian menurunkan angka kejadian mual dan muntah pascaoperasi, walaupun beberapa penelitian gagal untuk mencapai kemaknaan statistik karena power penelitian yang kurang, sehingga dibutuhkan penelitian dengan power yang lebih memadai untuk frekuensi yang lebih rendah (seperti pada muntah pascaoperasi) . ${ }^{17}$

Hasil penelitian ini menunjukkan bahwa pemberian cairan praoperatif sebanyak $2 \mathrm{~mL} /$ $\mathrm{kgBB} / \mathrm{jam}$ puasa ternyata efektif menurunkan angka kejadian mual pada 1 (satu) jam pertama pascaoperasi $(19,6 \%$ vs $39,2 \%)$, tetapi tidak terdapat perbedaan yang bermakna dalam hal kekerapan muntah baik satu jam pascaoperasi maupun 24 jam pascaoperasi.

Beberapa hal diperkirakan memengaruhi hasil penelitian ini, yaitu perhitungan jumlah cairan praoperatif yang tidak sesuai dengan jumlah cairan yang telah diberikan, monitoring pasien yang tidak adekuat sehingga pemberian cairan intraoperatif tidak terpelihara dengan baik, pengawasan dan monitoring 24 jam di ruangan tidak adekuat, serta cara pemberian tramadol sebagai analgesik pascaoperasi yang tidak tepat. Perhitungan cairan yang tidak tepat akan menyebabkan cairan yang diberikan tidak adekuat hingga tujuan pemberian cairan praoperatif untuk mencegah hipoperfusi usus tidak tercapai.

Pemberian cairan kristaloid sebanyak $2 \mathrm{~mL} /$ $\mathrm{kgBB} / \mathrm{jam}$ puasa sebelum dilakukan tindakan anestesi bertujuan memindahkan penggantian cairan puasa yang umumnya diberikan saat intraoperatif menjadi praoperatif. Kelemahan penggantian cairan puasa yang dilakukan saat intraoperatif ialah bahwa cairan tersebut tidak akan tergantikan secara penuh karena cairan pengganti puasa tersebut tergantikan secara penuh setelah 4 jam operasi berjalan, padahal prosedur mastektomi yang dilakukan hanya membutuhkan waktu sekitar 150 menit $(2,5$ jam). Menurut teoritis cairan pengganti puasa ini belum tergantikan, tetapi bila diperhatikan cairan intraoperatif pada kelompok kontrol mendekati banyaknya cairan praoperatif yang diberikan pada kelompok hidrasi, yaitu 1.200 (800-1.500) berbanding dengan 1.000 (5001.500), kondisi ini terkait dengan pengawasan 
intraoperatif yang tidak begitu memadai serta perhitungan cairan yang tidak teliti.

Hasil penelitian Moretti dkk. ${ }^{16}$ menyatakan bahwa pemberian cairan pra dan intraoperatif dalam jumlah yang sama menghasilkan angka kejadian mual dan muntah pascaoperasi yang sama. ${ }^{16}$ Penggantian cairan puasa praoperatif (baik intra maupun praoperatif) sendiri saat ini sedang menjadi suatu perdebatan, Chappel dan Jacob ${ }^{18}$ dalam beberapa tulisannya telah menyatakan bahwa puasa praoperatif tidak menimbulkan perubahan pada volume darah. Chappel dan Jacob ${ }^{18}$ tidak menyarankan untuk dilakukan penggantian cairan puasa dan lebih menyarankan penggunaan vasopresor bila terjadi hipotensi saat induksi. Bahkan, Chappel dan Jacob ${ }^{19}$ menyatakan bahwa penggunaan cairan yang berlebih saat praoperatif maupun intraoperatif tidak berpengaruh pada angka kejadian mual muntah pascaoperasi.

Penggunaan tramadol-parasetamol sebagai analgesia pascaoperasi mungkin merancukan hasil yang didapat penelitian ini. Tramadolparasetamol yang bersifat inhibitor re-uptake serotonergik dan agonis serotenergik sehingga akan memicu terjadi mual muntah, sekalipun pemberiannya dilakukan dengan drip selama 15 menit. Belum terdapat penelitian yang jelas tentang perbandingan mual muntah tramadolparasetamol intravena secara kontinu dengan bolus. $^{20}$

Pengawasan saat pasien telah dipindahkan ke ruangan menjadi kendala dan juga perancu tersendiri. Pemberian obat berbentuk cairan hampir tidak dapat diintervensi serta menjadi wewenang penuh operator dan juga perawat di ruangan. Pemberian antiemetik merupakan suatu hal yang rutin dan pemberian analgesik pascaoperasi (tramadol $2 \mathrm{mg} / \mathrm{kgBB}$ ) hampir pasti diberikan secara bolus melalui intravena, sedangkan pemberian tramadol secara bolus akan meningkatkan mual muntah yang akan merancukan penilaian mual muntah dalam 24 jam pertama.

Pada penelitian ini pasien dikembalikan ke ruangan setelah skor Aldrette minimal 8. Saat itu pasien sudah dapat aktif berkomunikasi dan hemodinamik stabil. Selalu dituliskan juga bahwa antiemetik tidak perlu diberikan secara rutin dan dapat diberikan bila pasien mengeluh mual ataupun muntah. Beberapa kejadian yang mungkin dapat merancukan hasil penelitian ini adalah pasien biasanya baru minum, makan per oral sore hari setelah dilakukan operasi saat pagi hari, cairan infus biasanya diberikan dalam jumlah terbatas dan minimal, obat-obat antiemetik seperti ondansentron menjadi hal yang sudah rutin diberikan walaupun pasien tidak mengeluhkan mual atau muntah.

\section{Simpulan}

Pemberian cairan praoperatif Ringer laktat 2 $\mathrm{mL} / \mathrm{kgBB} / \mathrm{jam}$ puasa menurunkan insidensi mual pascamastektomi saat 1 jam pascaoperasi (19,6\%vs39,2\%), namun tidak menunjukkan kemaknaan insidensi muntah pascamatektomi baik 1 (satu) jam maupun 24 jam pascaoperasi. Risiko relatif untuk terjadinya mual muntah pascaoperasi mastektomi adalah $0,52(0,28-$ $0,97)$ kali pada pasien yang diberikan cairan praoperatif Ringer laktat bila dibandingkan dengan pasien yang tidak mendapatkan cairan praoperatif.

\section{Daftar Pustaka}

1. Gan TJ, Meyer TA, Apfel CC, Chung F, Davis PJ, Habib AS, dkk. Society for ambulatory anesthesia guidelines for the management of post operative Nausea and vomiting. Anesth Analg. 2007;105:1615-28.

2. Habib SA, Gan TJ. Combination therapy for post operative nausea and vomiting more effective prophylaxis?. Ambulatory Surg. 2001(9):59-71.

3. Sighal AK. 5HT3 antagonist for prophylaxis of post operative nausea and vomiting in breast surgery: a meta analysis. J Postgrad Med. 2012 Jan-Mar;58(1):23-31.

4. Adanir T, Aksun M, Ozgürbüz U, Altin F, Sencan A. Does preoperative hydration affect post operative nausea and vomiting? A randomized control trial. J Laparoendoscopic and Advanced Surgical Techniques. 2008;18:1-5.

5. White PF, Zhao M, Tang J, Wender 
RH, Yumul R, Sloninsky AV, dkk. Use of disposable acupressure device as part of a multimodal antiemetic strategy for reducing postoperative nausea and vomiting. Anesth Analg. $2012 ; 115: 31-7$.

6. White PF. Are nonpharmacologic techniques useful alternatives to emetic drugs for the prevention of nausea and vomiting?. Anesth Analg. 1997;84:712-4.

7. Ali SZ, Taguchi A, Holtmann B, Kurz A. Effect of supplemental preoperative fluid on postoperative nausea and vomiting. Anesthesia. 2003;58:775-803.

8. Tang J, Watcha MF, White PF. Comparison of costs and efficacy of ondansentron and droperidol as prophylactic antiemetic therapy for elective outpatient gynecologic procedure. Anesth Analg. 1996;83:304-13.

9. Kovac AL. Prevention and treatment of post operative nausea and vomiting. Drugs. 2000;59(2);213-43.

10. Sadharivan S, Saxena A, Kathrivel S, Kannan TR, Trikha A, Mohan V. The safety and efficacy of prophylactic ondansentron in patient undergoing modified radical mastectomy. Anesth Analg. 1999;89:13405.

11. Apfel CC, Laara E, Koivuranta M.Asimplified risk score for predicting post operative nausea and vomiting. Anesthesiology. 1999;91:693-700.

12. Maharaj CH1, Kallam SR, Malik A, Hassett P, Grady D, Laffey JG. Preoperative intravenous fluid therapy decreases postoperative nausea and pain in high risk patients. Anesth Analg. 2005;100:675-82.

13. Apfel CC, Heidrich FM, Jukar-Rao S, Jalota L, Hornuss C, Whelan RP, dkk.
Evidence based analysis of risk factors for postoperative nausea and vomiting. $\mathrm{Br} \mathrm{J}$ Anaesth. 2012;276:1-12.

14. Chandrakantan A, Glass PA. Multimodal therapies for postoperative nausea and vomiting and pain. Br J Anaesth. 2011;107:127-40.

15. Amireh AM, Al Ghoul, Jabir IA. Preoperative intravenous fluid supplements: a simple and inexpensive method to reduce postoperative nausea and vomiting among patient underwent laparoscopic cholecystectomy. J Royal Medical Services. 2009 Dec;16(3):31-7.

16. Moretti EW, Robertson KM, El Moalem $\mathrm{H}$, Gan TJ. Intraoperative colloid administration reduces post operative nausea and vomiting and improves post operative out comescompared with crystalloid administration. Anesth Analg. 2003;96:611-7.

17. Apfell CC, Meyer A. Supplemental intravenous crystalloid for preventing post operative nausea and vomiting: a quantitative review. Br J Anesth. 2012; 108(6):893-902.

18. Chappel D, Jacob M. Blood volume is normal after preoperative overnight fasting. Acta Anesthesiol Scand. 2008(52):522-8.

19. Chappel D, Jacob M. A rational approach to perioperative fluid management. Anesthesiology. 2008(109):723-40.

20. Macintyre EP, Scott DA, Schug SA, Visser EJ, Walker SM. Systematically administered analgesic drugs in acute pain management: scientific evidence. Edisi ke-3. Melbourne: ANZCA \& FPM; 2010. 